\title{
Day surgery in a teaching hospital: identifying barriers to productivity
}

\author{
Abdelmonim E. A Salih ${ }^{1}$, Babak Meshkat ${ }^{1}$, Gary A Bass ${ }^{1}$, Seamus McHugh ${ }^{1}$, Sinead Fox ${ }^{2}$, Thomas \\ N Walsh ${ }^{1}$
}

1. Royal College of Surgeons in Ireland, Academic Department of Surgery, Connolly Hospital, Blanchardstown, Dublin, I reland. 2. Connolly Hospital Blanchardstown, Dublin, Ireland.

Correspondence: Abdelmonim E. A Salih. Address: Academic Department of Surgery, Connolly Hospital, Blanchardstown, Dublin 15, Ireland. E-mail: monim.salih@yahoo.ie

Received: September 2, 2014

DOI : $10.5430 /$ jha.v3n6p216
Accepted: October 17, 2014

URL: http://dx.doi.org/10.5430/jha.v3n6p216

\section{Abstract}

Introduction: Ambulatory surgery is a standard of care for many surgical procedures due to cost-effectiveness and benefits to patients including the reduced risk of contracting hospital infection by reducing the hospital stay. However, late cancellations can be costly. We examined the utilisation of the surgical day ward in our institution over a four-year period.

Methods: A retrospective study of surgical day ward records from September 2007 to September 2011 in one institution. Parameters investigated included the number of planned admissions. Reasons for cancellations were also collected.

Results: A total of 17,461 procedures were intended as a day ward admission during the study interval. There were 3,539 procedures that were cancelled (20.3\%). The prevalent proportion of cancellations $(n=1,367)(38.6 \%)$ were due to patients not showing up for their procedures (7.8\% of planned admissions); 1,188 (33.6\%) patients were cancelled by the admissions office due to bed shortages, accounting for $6.8 \%$ of planned admissions and 650 (18.4\%) of cases were due to last minute cancellations by patients, accounting for 3.7\% of all planned admission. The remaining 334 (9.4\%) of cases were cancelled on medical grounds including patients who were considered unfit for the intended procedure, or anti-coagulations not appropriately ceased prior to surgery, accounting for 1.9\% of all planned admissions.

Conclusion: The cancellation rate in this study was high, mainly due to failure of patients to attend or signal their intentions, inadequate bed capacity and bed closure strategies. The ring fencing and protection of day beds and a more active patient management interaction would have had the greatest impact on increased efficiency.

\section{Key words}

Day surgery, Ambulatory surgery, General surgery, Cost-effective

\section{I ntroduction}

Ambulatory surgery is the standard of care for many surgical procedures. It is more convenient for patients, separating planned from emergency surgery and more cost-effective for the health service ${ }^{[1]}$. Patient-perceived benefits of day surgery include treatment suiting their lifestyle needs while allowing them to recover in their home environment ${ }^{[2]}$. Reduction in hospital stay minimises the risk of hospital-acquired infection ${ }^{[3]}$ while providing high-quality cost-efficient 
care ${ }^{[4]}$. Day surgery appointments are susceptible to last minute cancellations, however, which can cause costly effects to both patients and the health service.

Monitoring late cancellations provides valuable insight into the efficiency of day care services. These data should inform protocols and policies used when selecting patients and procedures to maximise the clinical benefit and ensure safe practice. A dedicated day-care team should be able to provide the pre-operative assessment and investigations to avoid delays and cancellations ${ }^{[5]}$.

Expert consensus (The Audit Commission "Basket of 25") in the form of Basket $2000^{[6,7]}$ and the British Association of Day Surgery "trolley of procedures", have helped develop a list of 25 commonly performed procedures suitable for daycase management ${ }^{[6,7]}$. Subsequent outcome-based revisions derived from clinical practice in day-surgery units identified barriers to achieving maximum utilisation ${ }^{[8-10]}$. These included insufficient use of day surgery units, poor management, poor organisation and clinicians' preferences for inpatient surgery. With increasing financial constraints, improvements in service efficiency while ensuring highest-quality care are of utmost importance. A short audit of day-surgery has been previously published demonstrating increased efficiencies in an Irish rural general hospital ${ }^{[11]}$.

The aim of this study was to evaluate the utilisation of the surgical day ward in our institute, which have a large mixed rural and urban catchment area over a four-year period, focussing on late cancellations as a metric of performance.

\section{Methods}

A retrospective review of the surgical day ward (DW) records, theatre registry book and patients' medical records was conducted from September 2007 to September 2011. Parameters investigated included the number of planned procedures through the DW (including general anaesthetic, local anaesthetic, sedation and endoscopic procedures), number of admissions and performed procedures, number of late cancellations and the reason for cancellation. Late cancellation in this study was defined as any cancellation on the day of planned procedure leading to unused day bed and theatre time. Data from the DW records were correlated with theatre registry book to ensure accurate recording of performed procedures. In cases of late cancellations, DW records were correlated with patient medical records to confirm or clarify underlying reason. The collected data were tabulated into SPSS V.15 and results are presented using descriptive statistics.

\section{Results}

\subsection{Day ward availability}

Allowing for day ward closures for public holidays, (nine days each year in Ireland) there were a total 1,007 working-days during the study period during which 13,922 procedures were performed in the surgical day ward. The DW was closed by hospital management for varying lengths during the 4-year period, as part of a cost-containment exercise to meet financial targets. The day ward was only operational for a total of 869 days during the study period, because of the loss of 138 working days (see Table 1). This equates to a loss of 2,208 potential procedures during the study period calculated using an average of 16 procedures per day.

Table 1. Unused days in each individual year

\begin{tabular}{llllll}
\hline Period & Total working days & Bank holidays & Working days & Days DW closed & Days DW open \\
\hline 01 Sep 2007 - 31 Aug 2008 & 260 & 9 & 251 & 20 & 231 \\
01 Sep 2008 - 31 Aug 2009 & 261 & 9 & 252 & 63 & 189 \\
01 Sep 2009 - 31 Aug 2010 & 261 & 9 & 252 & 45 & 207 \\
01 Sep 2010 - 31 Aug 2011 & 261 & 9 & 252 & 10 & 242 \\
Total & 1,043 & 36 & 1,007 & 138 & 869 \\
\hline
\end{tabular}

Note. DW = Surgical Day Ward

Published by Sciedu Press 


\subsection{Procedures}

The total number of intended admissions to the DW was 17,461 during the study interval. A total of 13,922 procedures were performed (79.7\%) and 3,539 procedures were cancelled (20.3\%). The breakdown of each year included in this study is detailed in Table 2. General surgical admissions accounted for $58.7 \%(n=8,172)$, with orthopaedic procedures accounting for a further $17.9 \%(\mathrm{n}=2,492)$. Urological, plastics and gynaecological admissions accounted for $7.4 \%$ $(n=1,030), 8.5 \%(n=1,183)$ and 2.9\% $(n=404)$ respectively. Dental admissions accounted 2.8\% $(n=390)$, medical admissions accounted for the remaining $1.8 \%(\mathrm{n}=251)$. Most cases were done under sedation and LA accounting for $37.3 \%$ and $33.2 \%$ respectively. Procedures performed under GA accounted for $26.6 \%$ of procedures, with the remaining $2.9 \%$ requiring neither anaesthesia nor sedation.

Table 2. Total number of procedures each year

\begin{tabular}{llll}
\hline Period & No. Procedures performed & No procedures cancelled & Total On DW List \\
\hline Sep/07-Aug/08 & 3,753 & 933 & 4,686 \\
Sep/08-Aug/09 & 2,960 & 778 & 3,738 \\
Sep/09-Aug/10 & 3,648 & 852 & 4,500 \\
Sep/10-Aug/11 & 3,561 & 976 & 4,537 \\
Total & 13,922 & 3,539 & 17,461 \\
\hline
\end{tabular}

Note. $\mathrm{DW}=$ Surgical Day Ward

\subsection{Cancellations}

The majority of cancellations ( $\mathrm{n}=1,367)$ were due to patients who did not show up for their procedures and had not called to reschedule (38.6\% of cancellations and $7.8 \%$ of planned admissions). A total of 1,188 cases were cancelled by the admissions office due to the non-availability of hospital beds, representing $33.6 \%$ of cancellations and $6.8 \%$ of planned procedures. Six hundred and fifty procedures were cancelled due to patients rescheduling their procedures on the day of surgery $(18.4 \%)$. Medical grounds for cancellation $(n=334)$ accounted for $9.4 \%$ of all cancellations and $1.9 \%$ of all planned admissions. These included patients who were considered unfit for the intended procedure, or anti-coagulations not appropriately ceased prior to surgery. A detailed breakdown of reasons for cancellation on each year is demonstrated in Table 3.

Table 3. Reasons for cancellation

\begin{tabular}{llllll}
\hline & DNA (n) & Cancelled By admission office (n) & Self-Cancelled (n) & Other (n) & Total \\
\hline Sep/07-Aug/08 & $41.3 \%(385)$ & $33.1 \%(309)$ & $19.8 \%(185)$ & $5.8 \%(54)$ & $100 \%(933)$ \\
Sep/08-Aug/09 & $37.4 \%(291)$ & $33.0 \%(257)$ & $19.2 \%(149)$ & $10.4 \%(81)$ & $100 \%(778)$ \\
Sep/09-Aug/10 & $43.4 \%(370)$ & $22.0 \%(187)$ & $22.9 \%(195)$ & $11.7 \%(100)$ & $100 \%(852)$ \\
Sep/10-Aug/11 & $32.9 \%(321)$ & $44.5 \%(434)$ & $12.5 \%(122)$ & $10.1 \%(99)$ & $100 \%(976)$ \\
\hline
\end{tabular}

Note. DNA = Did Not Attend

\section{Discussion}

Day surgery is defined as the process of admitting carefully selected patients for elective surgery to the hospital on the day of their planned procedure and discharged on the same day ${ }^{[12]}$. This treatment paradigm has been shown to benefit the health service by reducing the cost of procedures when carried out on day-case basis with high rates of patient's satisfaction ${ }^{[13-15]}$. This also simultaneously improves throughput of patients, facilitating booking, and reducing waiting lists. But cancellations can be costly, especially if the hospital is not informed.

The cancellation rate in our institute was high but comparable to the rates reported in the literature, which ranged between $11.9 \%$ and $23 \%{ }^{[16-21]}$. The most common reason for late cancellation in this study was patients self-cancelling and not 
attending for their appointments. Late cancellations are undesirable to patients, the hospital and health service. They constitute lost working days for patients and families and as rearrangements are required they are costly to the hospital ${ }^{[22]}$. Furthermore, the loss of theatre time incurs further costs and denies other patients timely access to surgery ${ }^{[23]}$. Recognising that maximum efficacy of day surgery units requires the minimization of patient non-attendances, many initiatives have been described including postal questionnaires ${ }^{[24]}$, telephone call screening ${ }^{[25]}$ and telephone reminders. Basu et al. ${ }^{[24]}$ used postal questionnaire and telephone calls to reduce the cancellation rate from $12 \%$ to $2.5 \%$. Similarly, Haufler et al. ${ }^{[25]}$ used a nurse led telephone screening to reduce their cancellation rate.

A substantial number of cancellations were secondary to non-availability of beds, an issue that has been highlighted previously ${ }^{[26]}$. This was predominantly due to overflow of patients admitted through the Emergency Department (ED) requiring that beds in the DW be assigned to ED patients. In addition the DW was closed for 138 days as a hospital cost-containment strategy. As the hospital theatres were fully staffed and supported during these periods, the closure of the day ward may represent a false economy. We believe this highlights the need for "ring-fencing" of the DW beds as essential to DW efficiency ${ }^{[27]}$.

Procedures cancelled by the patient's surgical team on clinical grounds accounted for $9.4 \%$ of patient's cancellations. Examples of reasons for such cancellations included insufficient pre-operative workup, anti-coagulant not withheld pre-operatively where indicated or patient no longer requiring surgical intervention. Pre-assessment clinics have been shown to significantly diminish cancellation rate due to these factors ${ }^{[28-30]}$. These clinics address patient expectations and increase understanding of the proposed procedure. In addition pre-operative assessment clinics provide a thorough assessment of fitness for surgery and an assessment of social and home circumstances ${ }^{[28,30]}$. The findings of this present study informed the introduction of a pre-assessment clinic in our institution. We believe that this will reduce the rate of late cancellation and thus improve day ward turnover and productivity.

\section{Conclusion}

The cancellation rate in our institute was high. These findings suggest reduction in utilisation of the surgical day ward when support structures such as pre-admission patient interactive protocols and pre-assessment clinics are lacking. Reduced bed capacity and overflow of patients from the emergency department also negatively impact on the DW productivity. The introduction of measures such as phone or text message reminders to reduce cancellation rates, protected day beds and pre-assessment clinics improve productivity and lead to better utilisation of day surgery facilities.

\section{Acknowledgments}

The authors thank all the staff that helped in this research.

\section{Conflict of interests}

The authors declare that they have no conflict of interests.

\section{Reference}

[1] Coll AM, Moseley L, Torrance C. Fine tuning the day surgery process. Nursing standard. 1999; 14(4): 39-41. Epub 2000/06/16. PMID: 10855175. http://dx.doi.org/10.7748/ns1999.10.14.4.39.c2692

[2] Chung F. Recovery pattern and home-readiness after ambulatory surgery. Anesthesia and analgesia. 1995; 80(5): 896-902. Epub 1995/05/01. PMID: 7726431.

[3] Vilar-Compte D, Roldan R, Sandoval S, Corominas R, De La Rosa M, Gordillo P, et al. Surgical site infections in ambulatory surgery: a 5-year experience. American journal of infection control. 2001; 29(2): 99-103. Epub 2001/04/05. PMID: 11287877. http://dx.doi.org/10.1067/mic.2001.112241

[4] Shnaider I, Chung F. Outcomes in day surgery. Current opinion in anaesthesiology. 2006; 19(6): 622-9. Epub 2006/11/10. PMID: 17093366. http://dx.doi.org/10.1097/ACO.0b013e328010107e

Published by Sciedu Press 
[5] Sabeen Khan RA. Day case anaesthesia. Surgery (Oxford). 2011; 29(3): 122-5. Epub 22 February 2011. http://dx.doi.org/10.1016/j.mpsur.2010.11.022

[6] Skues M. Benchmarking in day and short stay surgery. Day Surgery and Enhanced Recovery. 2010.

[7] Cahill CJ. Basket cases and trolleys - day surgery proposals for the millennium. J One-Day Surg. 1999; 9(1): 11-2.

[8] A short cut to better services: day surgery in England and Wales. London: H.M.S.O. 1990.

[9] Brown PM, Fowler S, Ryan R, Rivron R. ENT day surgery in England and Wales--an audit by the Royal College of Surgeons (Eng.) Comparative Audit Service. The Journal of laryngology and otology. 1998; 112(2): 161-5. Epub 1998/05/14. PMID: 9578876.

[10] Ganesan S, Prior AJ, Rubin JS. Unexpected overnight admissions following day-case surgery: an analysis of a dedicated ENT day care unit. Annals of the Royal College of Surgeons of England. 2000; 82(5): 327-30. Epub 2000/10/21. PMID: 11041031.

[11] Concannon ES, Hogan AM, Flood L, Khan W, Waldron R, Barry K. Day of surgery admission for the elective surgical in-patient: successful implementation of the Elective Surgery Programme. Irish journal of medical science. 2013; 182(1): 127-33. Epub 2012/09/12. PMID: 22965814. http://dx.doi.org/10.1007/s11845-012-0850-5

[12] Castoro C, Bertinato L, Baccaglini U, Drace CA, McKee M. Day Surgery: Making it Happen. 2007.

[13] Ng D, Hutchinson S, Pohl M, Powell B. Sentinel lymph node biopsy for malignant melanoma as day surgery. Journal of plastic, reconstructive \& aesthetic surgery: JPRAS. 2007; 60(6): 631-4. Epub 2007/05/09. PMID: 17485050. http://dx.doi.org/10.1016/j.bjps.2006.11.030

[14] Vijay V, Halbert J, Zissimopoulos A, Siddiqi S, Warren S. Day case laparoscopic rectopexy is feasible, safe, and cost effective for selected patients. Surgical endoscopy. 2008; 22(5): 1237-40. Epub 2007/10/19. PMID: 17943362. http://dx.doi.org/10.1007/s00464-007-9598-9

[15] Ahmad NZ, Byrnes G, Naqvi SA. A meta-analysis of ambulatory versus inpatient laparoscopic cholecystectomy. Surgical endoscopy. 2008; 22(9): 1928-34. Epub 2008/04/10. PMID: 18398648. http://dx.doi.org/10.1007/s00464-008-9867-2

[16] Hand R, Levin P, Stanziola A. The causes of cancelled elective surgery. Quality assurance and utilization review: official journal of the American College of Utilization Review Physicians. 1990; 5(1): 2-6. Epub 1990/02/01. PMID: 2136658.

[17] Lacqua MJ, Evans JT. Cancelled elective surgery: an evaluation. The American surgeon. 1994; 60(11): 809-11. Epub 1994/11/01. PMID: 7978670.

[18] Aguirre-Cordova JF, Chavez-Vazquez G, Huitron-Aguilar GA, Cortes-Jimenez N. [Why is surgery cancelled? causes, implications, and bibliographic antecedents]. Gaceta medica de Mexico. 2003; 139(6): 545-51. Epub 2004/01/16. PMID: 14723050.

[19] Schofield WN, Rubin GL, Piza M, Lai YY, Sindhusake D, Fearnside MR, et al. Cancellation of operations on the day of intended surgery at a major Australian referral hospital. The Medical journal of Australia. 2005; 182(12): 612-5. Epub 2005/06/21. PMID: 15963016.

[20] Paschoal ML, Gatto MA. [Rate of surgery cancellation at a university hospital and reasons for patients' absence from the planned surgery]. Revista latino-americana de enfermagem. 2006; 14(1): 48-53. Epub 2006/03/15. PMID: 16532239. http://dx.doi.org/S0104-11692006000100007

[21] Sanjay P, Dodds A, Miller E, Arumugam PJ, Woodward A. Cancelled elective operations: an observational study from a district general hospital. Journal of health organization and management. 2007; 21(1): 54-8. Epub 2007/04/26. PMID: 17455812.

[22] Nasr A, Reichardt K, Fitzgerald K, Arumugusamy M, Keeling P, Walsh TN. Impact of emergency admissions on elective surgical workload. Irish journal of medical science. 2004; 173(3): 133-5. Epub 2005/02/08. PMID: 15693381.

[23] Henderson BA, Naveiras M, Butler N, Hertzmark E, Ferrufino-Ponce Z. Incidence and causes of ocular surgery cancellations in an ambulatory surgical center. Journal of cataract and refractive surgery. 2006; 32(1): 95-102. Epub 2006/03/07. PMID: 16516786. http://dx.doi.org/10.1016/j.jcrs.2005.11.013

[24] Basu S, Babajee P, Selvachandran SN, Cade D. Impact of questionnaires and telephone screening on attendance for ambulatory surgery. Annals of the Royal College of Surgeons of England. 2001; 83(5): 329-31. Epub 2002/01/25. PMID: 11806558.

[25] Haufler K, Harrington M. Using nurse-to-patient telephone calls to reduce day-of-surgery cancellations. AORN journal. 2011; 94(1): 19-26. Epub 2011/07/05. PMID: 21722768. http://dx.doi.org/10.1016/j.aorn.2010.12.024

[26] Robb WB, O'Sullivan MJ, Brannigan AE, Bouchier-Hayes DJ. Are elective surgical operations cancelled due to increasing medical admissions? Irish journal of medical science. 2004; 173(3): 129-32. Epub 2005/02/08. PMID: 15693380.

[27] Kjekshus LE, Hagen TP. Ring fencing of elective surgery: does it affect hospital efficiency? Health services management research: an official journal of the Association of University Programs in Health Administration/HSMC, AUPHA. 2005; 18(3): 186-97. Epub 2005/08/17. PMID: 16102247. http://dx.doi.org/10.1258/0951484054572529

[28] Reed M, Wright S, Armitage F. Nurse-led general surgical pre-operative assessment clinic. Journal of the Royal College of Surgeons of Edinburgh. 1997; 42(5): 310-3. Epub 1997/11/14. PMID: 9354062.

[29] Rai MR, Pandit JJ. Day of surgery cancellations after nurse-led pre-assessment in an elective surgical centre: the first 2 years. Anaesthesia. 2003; 58(7): 692-9. Epub 2003/07/31. PMID: 12886919.

[30] Knox M, Myers E, Hurley M. The impact of pre-operative assessment clinics on elective surgical case cancellations. The surgeon: journal of the Royal Colleges of Surgeons of Edinburgh and Ireland. 2009; 7(2): 76-8. Epub 2009/05/05. PMID: 19408797. 